\title{
ANÁLISES FÍSICAS E MORFOLÓGICAS DE Canavalia dictyota Piper
} (FABACEAE)

\footnotetext{
Edinalda Andrade Silva ${ }^{1}$, Maria da Conceição Sampaio Alves Teixeira ${ }^{2}$, Maura

Rejane Araújo Mendes ${ }^{3}$, Jesus Rodrigues Lemos ${ }^{4}$, Rafaelle Neves Freitas ${ }^{5}$

${ }^{1}$ Eng. Agrônoma pela Universidade Estadual do Piauí. Parnaíba, Piauí, Brasil

${ }^{2}$ Profa Doutora do Departamento de Biologia da Universidade Estadual do Piauí, Parnaíba-Brasil.ceicaotx@phb.uespi.br

${ }^{3}$ Profa Doutora do Departamento de Biologia da Universidade Estadual do Piauí, Parnaíba-Brasil.

${ }^{4}$ Prof. Doutor do Curso de Ciências Biológicas da Universidade Federal do Piauí, Campus Ministro Reis Velloso, Parnaíba-Brasil.

${ }^{5}$ Bióloga pela da Universidade Federal do Piauí, Parnaíba-Brasil.

Recebido em: 06/04/2019 - Aprovado em: 10/06/2019 - Publicado em: 30/06/2019

DOI: 10.18677/EnciBio_2019A12
}

\begin{abstract}
RESUMO
Este estudo teve como objetivo realizar as análises físicas e morfológicas de Canavalia dictyota Piper. Os frutos foram coletados na cidade de llha Grande, Piauí, Brasil. Foram realizadas: caracterização do fruto, da semente e da plântula. A análise morfométrica do fruto e da semente foi realizada por meio das dimensões de comprimento $(\mathrm{cm})$, largura $(\mathrm{mm})$ e espessura $(\mathrm{mm})$. A caracterização da germinação e descrição morfológica das plântulas foi feita por meio de observações diárias e realizados desenhos ilustrativos em tempo real. Concluiu-se que os aspectos morfológicos da semente, nas fases de germinação e plântulas de $C$. dictyota Piper são bastante homogêneos em todas as fases e confiáveis para a identificação da espécie. A germinação é do tipo epígea, fanerocotiledonar. Os fatores abióticos existentes nas regiões de predominâncias das espécies do gênero Canavalia podem influenciar na sua morfologia.
\end{abstract}

PALAVRAS-CHAVE: epígea; germinação; plântula; semente.

\section{PHYSICAL AND MORPHOLOGICAL ANALYSIS OF Canavalia dictyota Piper (FABACEAE)}

\begin{abstract}
This study had the goal of perform the physical and morphological analyses of Canavalia dictyota Piper. The fruits were collected in the city of Ilha Grande, Piauí, Brazil. Were carried out: the characterization of the fruit, the seed and the seedling. The morphometric analysis of the fruit and seed was performed by means of length $(\mathrm{cm})$, width $(\mathrm{mm})$ and density $(\mathrm{mm})$. The characterization of the germination and morphological description of the seedlings was done through daily observations and
\end{abstract}


carried out illustrative drawings in real time. It was concluded that the morphological aspects of the seed, in the phases of germination and seedlings of $C$. dictyota Piper are quite homogeneous in all phases and reliable for the identification of the species. The germination is of the epigeous type, phanerocotyledonar. The abiotic factors existing in the regions of predominance of the species of the genus Canavalia can influence its morphology.

KEYWORDS: epigeal; germination; seedling; seed.

\section{INTRODUÇÃO}

O gênero Canavalia possui cerca de 60 espécies, das quais, 17 espécies ocorrem no Brasil distribuídas nos estados do Norte, Nordeste e Centro - Oeste. As espécies do gênero podem ser caracterizadas pelo hábito lianescente e folhas trifolioladas (SNACK, 2019).

De acordo com o Brazil Flora Group (BFG, 2015) Fabaceae é a família mais numerosa em quase todos os ecossistemas e biomas do país, inclusive na restinga. Informações sobre a germinação das sementes de restinga podem contribuir para a preservação das espécies neste ecossistema, além de proteger contra a ameaça de extinção.

As restingas são ecossistemas que compreendem um conjunto geomorfológico formado pela deposição de sedimentos arenosos de origem marinha e flúviomarinha, com diversas formações como barras, esporões e planícies ao longo do litoral do Brasil. Estas formações abrigam cobertura vegetal de fisionomia distinta, disposta em mosaicos e com grande diversidade ecológica, que apresentam formações vegetais herbáceas, arbustivas e arbóreas, e são definidas pelas condições dos solos e influência marítima (THOMAZI, et. al., 2013).

Os estudos da morfologia de frutos, sementes e de plântulas, como também da germinação de sementes, têm como importância caracterizar a morfologia morfológica e fornecer subsídios para diferenciar espécies e caracterizar aspectos ecológicos da planta, como a dispersão, estabelecimento de plântulas e fase da sucessão ecológica bem como auxiliar no processo da germinação e na produção de mudas de qualidade (LOPES ; MATHEUS, 2008; FILLIPPI et. al., 2012).

Nesse sentido, diversos trabalhos têm sido realizados com o intuito de fornecer esse tipo de informação, como os desenvolvidos por Reis et al. (2016) com Apuleia molaris Spruce ex Beth.; Mendonça et al. (2016) com Poincianella pyramidalis (Tul.) L. P. Queiroz; Duarte et al. (2016) com Hymenaea courbaril L.; Pontes et al. (2018) com Annona reticulata (L.) Vell. e Oliveira et al. (2018) com Jacaranda mimosifolia D. Don. Esses aspectos são considerados fundamentais do ponto de vista ecológico pois podem subsidiar programas de reflorestamentos e recuperação de áreas degradadas (FERREIRA et al., 2015).

A morfologia vegetal em si pode ser identificada de forma visual, a olho nu, e interpretada minuciosamente por meio de desenhos manuais de cada fase de desenvolvimento. Para isto, faz-se necessário o acompanhamento diário, desde a absorção da água, protrusão da radícula até o alongamento da plântula. Como forma de uma visualização mais precisa, utiliza-se um material sofisticado como câmeras digitais, para obtenção de fotos em tempo real. Neste sentido, o estudo morfológico é de extrema importância para a caracterização de novas espécies e tem aumentado, especificamente com sementes, pois estas, como é sabido, são 
uma importante garantia de sobrevivência das espécies vegetais (DUARTE et al., 2015).

Além da caracterização morfológica, cabe salientar a importância dos estudos que enfocam o potencial germinativo das sementes (DUARTE et al., 2015). Ainda segundo estes autores, para que a germinação de sementes ocorra com sucesso é necessário que esta esteja em estágio fisiológico adequado, e, para isto, torna-se necessário realizar o beneficiamento das sementes, retirando impurezas e sementes com características indesejáveis.

Abud et al. (2010) ressaltam que as sementes são constituídas, em sua grande maioria, por embrião, endosperma e tegumento, sendo estes elementos fortemente influenciados por diferenças ambientais ou adaptações evolutivas, podendo variar morfologicamente entre espécies ou até mesmo entre indivíduos.

Por outro lado, apesar de serem formadas basicamente por embrião, tecidos de reserva e envoltório, diversos fatores na natureza contribuem para que haja desenvolvimento diferenciado dos componentes da semente, variando entre, e até dentro da própria espécie, em aspectos como cor, forma e tamanho, de modo que desempenhem uma função fundamental na renovação, persistência e dispersão das populações de plantas, regeneração das florestas e sucessão ecológica (DORIA, 2010).

É sabido que o tamanho ou o peso das sementes influenciam em seu desenvolvimento, o que significa que sementes mais pesadas possuem indicativo de qualidade fisiológica e que as sementes leves têm maior dificuldade para germinar ou até deixem de fazê-la. Assim, as informações fornecidas pela caracterização biométrica de frutos e de sementes são importantes e contribuem para a diferenciação de espécies do mesmo gênero (CRUZ et al., 2001) e de acordo com o tamanho das sementes, entende-se que interferem na necessidade de nutrientes e no espaço pelo qual irão necessitar, determinando a densidade e a profundidade de semeadura.

Diante de todas estas questões, ainda é visível que muitas espécies vegetais presentes no Piauí possuem carência de informações com este perfil. Há uma lacuna total para muitas espécies de Fabaceae, por exemplo, a qual corresponde a uma família bem representativa, em número de espécies, e importante do ponto de vista econômico e ecológico, destacando-se em muitos estudos realizados no Estado, especificamente na porção norte (AMARAL; LEMOS, 2015; CARVALHO et al., 2018; CERQUEIRA; LEMOS, 2018; LIMA et al., 2018; PEREIRA; LEMOS, 2018; SILVA; LEMOS, 2018).

Portanto, apesar de sua considerável distribuição geográfica, ainda existem poucos estudos sobre a morfologia das sementes e de plântulas de $C$. dictyota. Assim o objetivo deste estudo foi caracterizar frutos, sementes e plântulas de $C$. dictyota por meio de descrições e das características morfológicas externas.

\section{MATERIAL E MÉTODOS}

Os frutos foram coletados na cidade de Ilha Grande, na localidade "Santo

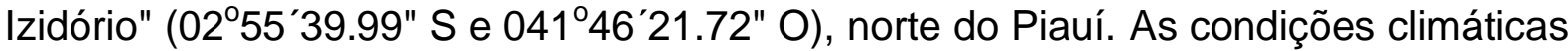
do município de Ilha Grande (com altitude da sede a $10 \mathrm{~m}$ acima do nível do mar) apresentam temperaturas mínimas de $25^{\circ} \mathrm{C}$ e máximas de $35^{\circ} \mathrm{C}$, com clima quente tropical. A precipitação pluviométrica média anual é definida no Regime Equatorial 
Marítimo, com isoietas anuais entre 800 a $1.600 \mathrm{~mm}$, cerca de 5 a 6 meses como os mais chuvosos e período restante do ano de estação seca (CPRM, 2004).

As amostras foram coletadas manualmente, colocadas em sacos plásticos e levados ao Laboratório de Biologia da Universidade Estadual do PiauíUESPI/Campus Parnaíba, onde foram conduzidos os procedimentos experimentais. A identificação da espécie foi realizada com o auxílio da bibliografia especializada (QUEIROZ, 2015).

Para a caracterização morfológica e descrição do fruto, foram utilizadas 25 amostras provenientes de matrizes diferentes. A análise morfométrica do fruto foi realizada após a sua coleta, com as dimensões de comprimento $(\mathrm{cm})$, largura $(\mathrm{mm})$ e espessura $(\mathrm{mm})$ verificadas com o auxilio de paquímetro digital mitutoyo (precisão de $0,01 \mathrm{~mm}$ ) e fita métrica. Para determinar a largura e a espessura, retirou-se a média das três regiões do fruto (ápice superior e inferior e região mediana). As ilustrações foram feitas a olho nu. Os frutos foram pesados com semente e retirada a diferença após o debulhe para a determinação do peso sem semente, obtendo média total de peso dos frutos com e sem semente.

Para a caracterização morfológica das sementes, foram descritas e ilustradas a partir de amostras de 30 unidades provenientes de diferentes indivíduos. A remoção das sementes de cada fruto foi feita manualmente. A análise morfométrica da semente foi realizada no final das coletas, em amostras aleatórias de 100 sementes, das quais dimensões como comprimento $(\mathrm{mm})$, largura $(\mathrm{mm})$ e espessura $(\mathrm{mm})$ foram verificadas com o auxilio de paquímetro digital com precisão de $0,1 \mathrm{~mm}$. $O$ comprimento foi medido da base ao ápice e a largura e espessura foram medidas na linha mediana das sementes. Determinou-se a média das dimensões, do peso e do número de sementes por fruto.

O procedimento metodológico para a morfologia do fruto e da semente de $C$. dictyota foi baseado nos trabalhos de Vidal e Vidal (2000), Barroso et al. (2004), Silva et al. (2008) e Queiroz e Bianco (2009).

A caracterização da germinação e descrição morfológica das plântulas foi feita semeando-se 30 sementes, em sacos plásticos, contendo areia peneirada e esterilizada. Utilizou-se a escarificação mecânica como tratamento pré-germinativo. Para a caracterização da plântula e das fases de germinação, foram descritos os processos de desenvolvimento dos estádios, por meio de observações diárias e realizados desenhos ilustrativos em tempo real. Essas observações foram realizadas desde 0 intumescimento da semente até 0 aparecimento dos protófilos, caracterizando assim, a plântula normal.

Para determinar o peso de mil sementes foi utilizada a média de oito repetições de 100 sementes, pesadas em balança com precisão de 0,001g. A condução do teste seguiu BRASIL (2009).

Para o estudo de absorção de água pela semente, inicialmente, cada subamostras de 20 sementes foi pesada e embebida em água destilada na temperatura ambiente por 1, 2, 3, 4, 5, 6, 7, 8, 24, 48 e 72 horas. Ao final de cada intervalo de tempo, as sementes foram novamente pesadas e em seguida colocadas no interior de estufa a $105^{\circ} \mathrm{C} \pm 3{ }^{\circ} \mathrm{C}$, por 24 horas, para determinação do grau de umidade final (BRASIL, 2009).

\section{RESULTADOS E DISCUSSÃO}


Na Figura 1, na qual está representada a massa úmida de sementes de $C$. dictyota, só foi possível visualizar a fase I das três fases fisiológicas de embebição, pois o incremento na massa úmida foi sempre crescente. Observa-se, ainda, na Figura 1 que o peso aumentou gradativamente. Em 48 horas, alterou-se para 0,32g, de modo que até às 72 horas não houve tendência de estabilização. Esse fato pode ter ocorrido devido às sementes de $C$. dictyota serem duras ou dormentes. Considera-se que, para obter tais resultados em novos testes, devem-se acompanhar a embebição das sementes de C. dictyota por mais de 72 horas, obtendo possivelmente resultados significativos.

A água é fator que exerce determinante influência no processo de germinação de sementes. A reidratação dos tecidos resulta da absorção de água pelas sementes com intensificação da respiração e demais atividades metabólicas, que fornecem energia e nutrientes para a retomada do crescimento do eixo embrionário. (BORGES et al., 2009). Entretanto, Carvalho e Nakagawa (2012) afirmam que em uma ou duas horas, esta fase pode completar-se.

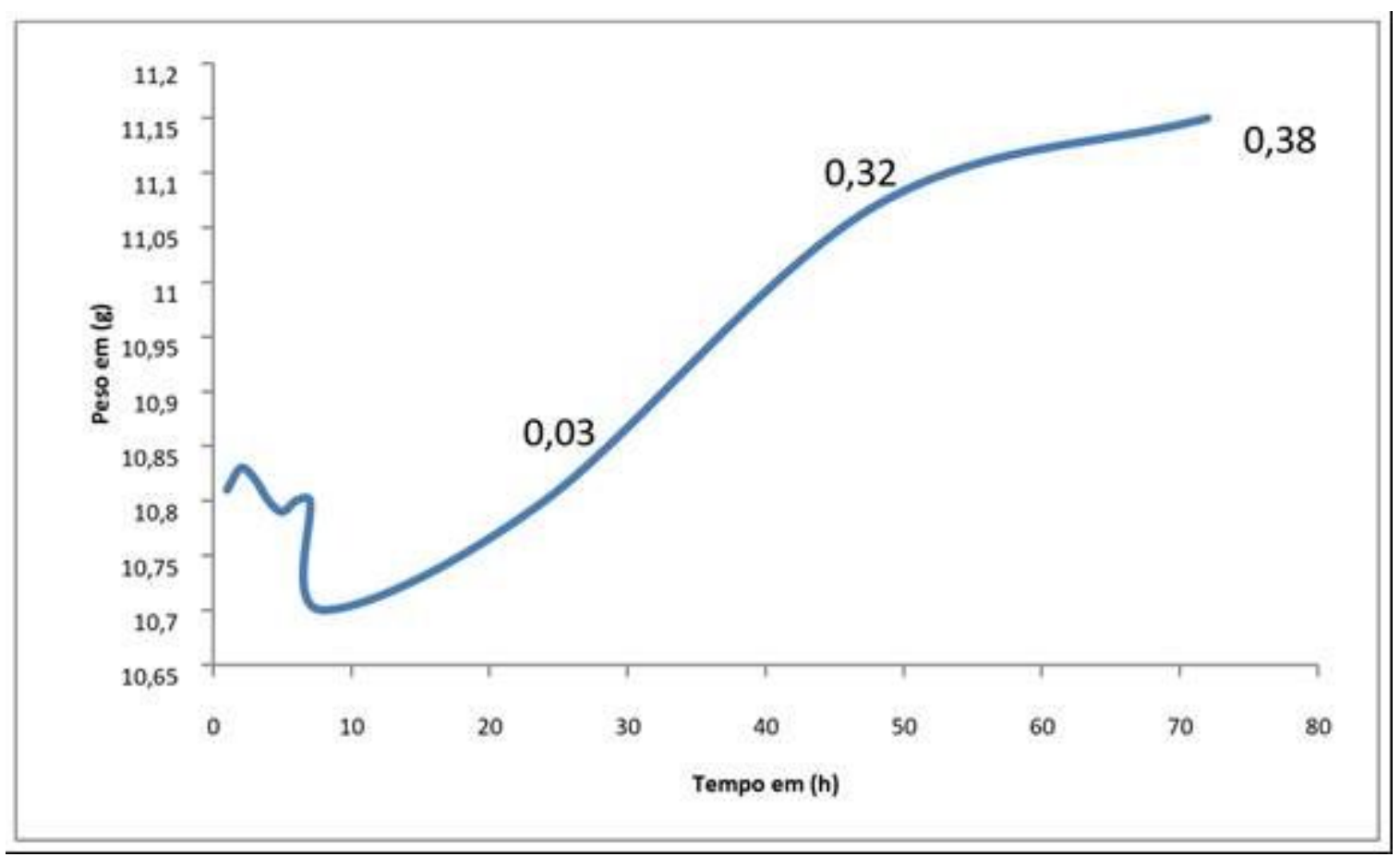

FIGURA 1. Curva de embebição por água pelas sementes de Canavalia dictyota Piper.

O fruto de C. dictyota Piper é do tipo legume, reto, unilocular (Figura 2), de cor castanho-alaranjada a marrom. A Tabela 1 mostra os dados biométricos do fruto de C. dictyota, onde suas dimensões mínimas foram de $8,08 \mathrm{~mm}$, máxima de 19,04 e média de $14,24 \mathrm{~mm}$ de comprimento por $6,94 \mathrm{~mm}$ a $10,52 \mathrm{~mm}$ de espessura. A largura variou de $15,38 \mathrm{~mm}$ a $22,71 \mathrm{~mm}$, com 4 a 13 sementes por fruto.

TABELA 1. Dados biométricos dos frutos de Canavalia dictyota Piper.

Frutos Mínimo Médio Máximo




\begin{tabular}{lccc}
\hline Comprimento $(\mathrm{cm})$ & 8,08 & 14,24 & 19,04 \\
Largura (mm) & 15,38 & 19,91 & 22,71 \\
Espessura (mm) & 6,94 & 9,21 & 10,52 \\
№ de sementes / fruto & 4,0 & 7,56 & 13,00 \\
\hline
\end{tabular}

Os frutos são unisseriados, septados, oblanceolados, achatados, simples, secos, ápice com rostro curvo, duas valvas deiscentes ao longo de toda sutura ventral, possuindo partes florais persistentes (Figura 2-D). O endocarpo apresenta textura papirácea e esfoliante (Figura 2E). Prado e Rodrigues (2013) observaram que o fruto de Canavalia dictyota coletado e estudado em Boa Vista, Roraima, Brasil, é do tipo legume, reto, unilocular, simples, seco. O peso dos frutos com semente variou de 3,16 a 18,10g. (Tabela 2). Correa et. al. (2008), também encontrou uma variação ampla, estudando o fruto de baru (Dipteryx alata), de 14,00 a $47,77 \mathrm{~g}$

TABELA 2. Peso dos frutos e sementes de C. dictyota Piper.

\begin{tabular}{lccc}
\hline Frutos / Sementes & Mínimo & Médio & Máximo \\
\hline Peso do fruto com semente $(\mathrm{g})$ & 3,16 & 10,76 & 18,10 \\
Peso do fruto sem semente $(\mathrm{g})$ & 1,25 & 5,99 & 10,85 \\
Peso de sementes / fruto $(\mathrm{g})$ & 1,90 & 4,76 & 9,08 \\
\hline Peso de 100 sementes $(\mathrm{g})$ & & Total & 60,73 \\
\hline
\end{tabular}
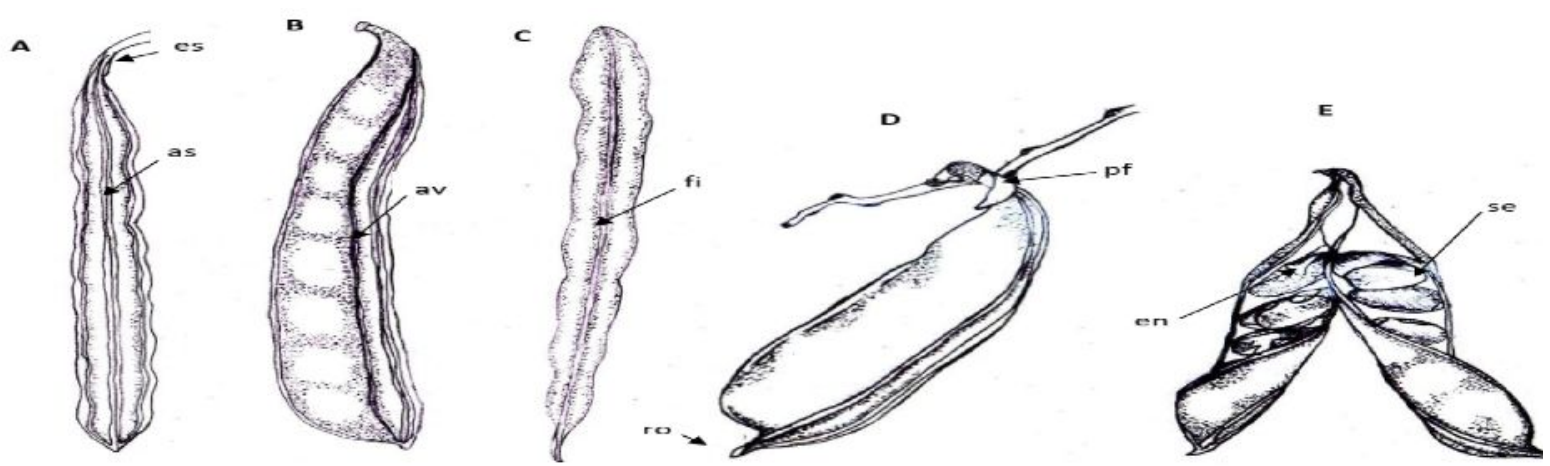

FIGURA 2. Morfologia do fruto e da semente de Análise de atributos físicos, da semente de Canavalia dictyota Piper. Fonte: Pesquisa direta (2019).

Legenda: (A) Vista frontal; (B-D) Vista lateral; (C) Vista inferior; (E) Legume após sua deiscência, (posição da semente no fruto); es-estípite; as- ala sutural; av- ala valvar; fi- fissuras no exocarpo; rorostro; pf- partes florais presentes; en- endocarpo com textura papirácea, esfoliante; se- semente.

Foi observado neste estudo que a $C$. dictyota possui uma semente lisa, coriácea, com coloração castanha amarelada, com leves manchas marrons, sem linhas de fraturas. É simétrica, comprimida lateralmente, de testa glabra, oblonga. Possui em média 14,38 mm de comprimento (variando de 11,62 a 15,77 mm), 9,97 de largura (variando de 8,41 a 10,72) e 5,97 de espessura (variando de 4,14 a 6,97) (Tabela 3). Prado e Rodrigues (2013), observaram resultados contrastantes das sementes de $C$. dictyota possuindo dimensões superiores, que variaram entre 14,817,5 comprimento, 9,7-12,3 de largura e 6,3-9,3 de espessura ( $\mathrm{mm}$ ), comprimida lateralmente, simétrica, oblonga, de coloração castanho-amarelada com manchas 
marrons opaca e levemente brilhantes, indicando uma alta variabilidade genética na população.

Essa diferença, segundo Dutra et al. (2017), pode ter sido influenciada por fatores bióticos e abióticos durante a formação e desenvolvimento de sementes. Porém, independente dos dados morfométricos os resultados possuem elevado valor ecológico, auxiliando na determinação da variabilidade da espécie, bem como no estudo da dispersão e agentes dispersores (Felippi; Araújo; Longhi, 2015).

TABELA 3. Dados biométricos das sementes de C. dictyota Piper. Parnaíba, Piauí.

\begin{tabular}{lccc}
\hline Sementes & Mínimo & Médio & Máximo \\
\hline Comprimento $(\mathrm{mm})$ & 11,62 & 14,38 & 15,77 \\
Largura $(\mathrm{mm})$ & 8,41 & 9,97 & 10,72 \\
Espessura $(\mathrm{mm})$ & 4,14 & 5,97 & 6,97 \\
\hline
\end{tabular}

Neste estudo, o peso de mil sementes foi de $589,35 \mathrm{~g}$, com um número de 1.696,76 sementes por quilograma. Para as sementes de $C$. dictyota, o teor médio de água registrado foi de $11,56 \%$ (Tabela 4). Segundo Piña-Rodrigues e Aguiar (1993), o peso e o tamanho das sementes alteram de local para local, país ou região, de acordo com determinada espécie e estas são características flexíveis, com o passar do tempo, de ano para ano, dentro e entre as matrizes.

TABELA 4. Análise de atributos físicos, da semente de Canavalia dictyota Piper.

\begin{tabular}{lc}
\hline ATRIBUTOS FÍSICOS & RESULTADOS \\
\hline Peso de 1000 Sementes & $589,35 \mathrm{~g}$ \\
Número de Sementes por Quilo & 1696,76 \\
$\%$ de Umidade & $11,56 \%$ \\
\hline
\end{tabular}

Após 24 horas após da semeadura, a semente de $C$. dictyota apresentou-se inchada, com coloração marrom escura. A germinação ocorreu no segundo dia. Foram consideradas germinadas, nesse trabalho, as sementes que apresentavam a protrusão da radícula. Observou-se também observar detalhadamente o momento da protrusão da radícula (FIGURA 3B). No terceiro e quarto dia, na radícula media $1,5 \mathrm{~cm}$ de comprimento, houve perca parcial do tegumento, alongamento do hipocótilo e no quinto dia emissão das raízes laterais (Figura 3C, 3D e 3E). Estes dados corroboram com Garwood (1995), o qual registrou que a germinação de $C$. dictyota deu-se em um período inferior a quatro dias, sendo considerada, portanto, como uma germinação imediata.

C. dyctiota emerge no solo após quatro dias de semeadura, permitindo assim observar a plântula ainda com a presença do tegumento, caracterizando uma germinação fanerocotiledonar e, o eófilo do primeiro nó, a partir do quinto dia (Figura 3 C-D; E-F). Os cotilédones são carnosos, plano-convexos, com 18,77mm de comprimento $\times 11,22 \mathrm{~mm}$ de largura e 3,98 $\mathrm{mm}$ de espessura. $O$ início da germinação de $C$. dictyota é semelhante ao observado para a espécie Canavalia rosea, a qual apresenta germinação fanerocotiledonar, rompendo o tegumento e emitindo a raiz principal em torno de dois dias após a semeadura (GONÇALVES et al., 2008).

Há a completa expansão do epicótilo no oitavo dia, a plântula apresenta coloração verde-escuro, vistosa e possui nervuras extremamente visíveis desde o 
quinto dia de desenvolvimento. Possuem raízes secundárias castanho-claro bem desenvolvidas em grande número entre 11 a 20 dias, além do surgimento do metáfilo com completa expansão do par de eófilos do primeiro nó (Figura $3 \mathrm{H}-\mathrm{I}$ ).

Com 20 dias de desenvolvimento, os eófilos de $C$. dyctiota possuem de $74,1 \mathrm{~mm}$ por $94,82 \mathrm{~mm}$ de comprimento e largura e $0,45 \mathrm{~mm}$ de espessura, em que pode-se observar nervuras ainda bem visíveis. As estípulas possuem $4,37 \mathrm{~mm}$ de comprimento por $3,43 \mathrm{~mm}$ de largura e $0,11 \mathrm{~mm}$ de espessura. Já nos metáfilos, observou-se uma média de 51,90 de comprimento x 36,73 mm largura por 0,48 mm de espessura. $\mathrm{O}$ hipocótilo possui dimensões de $32,32 \mathrm{~mm}$ de comprimento e 3,06 $\mathrm{mm}$ de diâmetro e o epicótilo com 26,67 mm comprimento por 2,84 mm de espessura, em média.

As características morfológicas de $C$. dictyota Piper estão parcialmente de acordo com Prado e Rodrigues (2013), diferenciando-se em aspectos tais como a coloração das sementes e plântulas com número superior de raízes secundárias, fatos estes que podem ser atribuídos aos fatores abióticos aos quais as plantas matrizes estão submetidas, tais como luz, disponibilidade hídrica e temperatura na região.

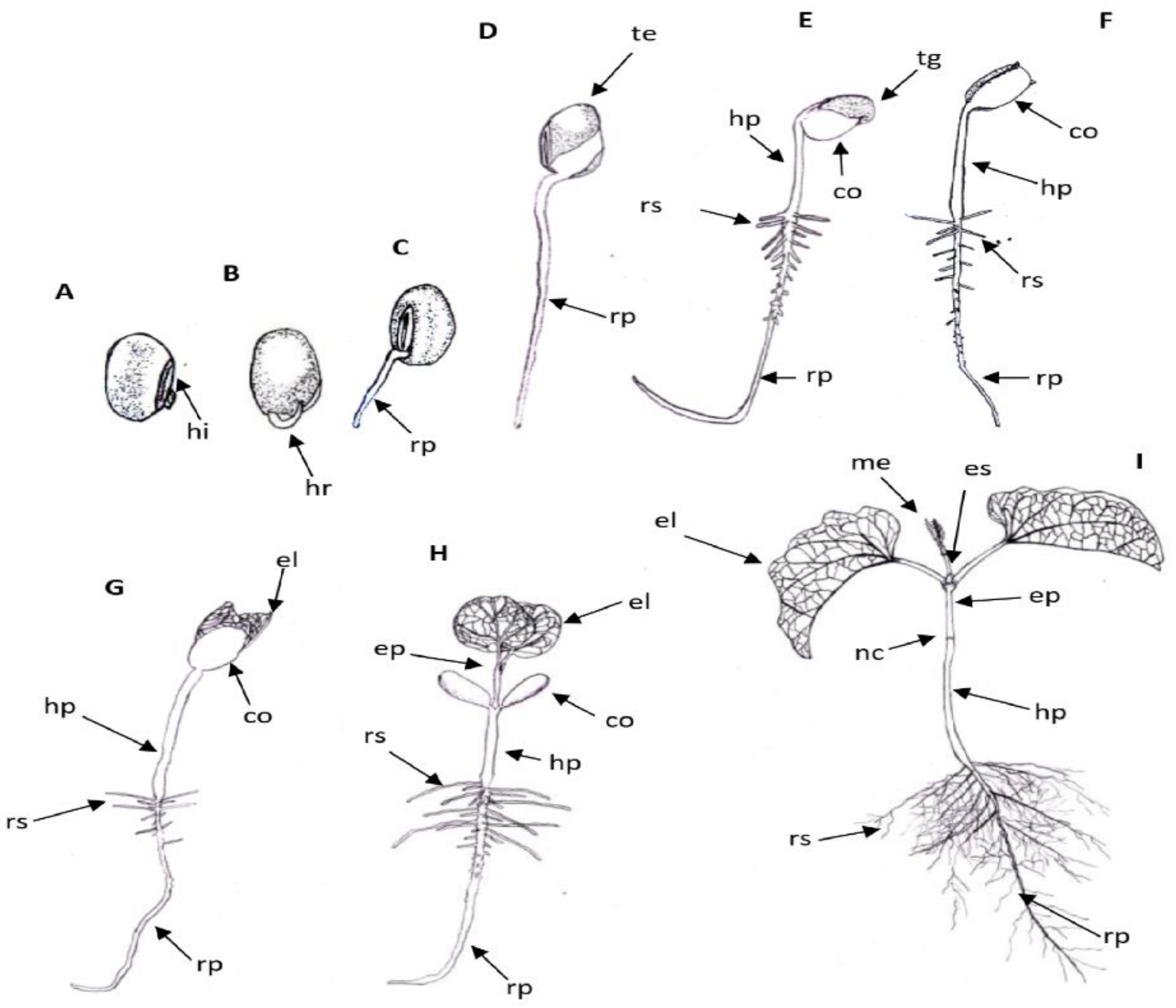


FIGURA 3. Fase da germinação e formação de plântula de Análise de atributos físicos, da semente de Canavalia dictyota Piper. Fonte: Pesquisa direta (2019).

\section{CONCLUSÕES}

Os frutos e as sementes de Canavalia dictyota apresentam grande variabilidade em relação ao comprimento, largura e espessura.

Os aspectos morfológicos da semente, nas fases de germinação, e plântulas de Canavalia dictyota Piper são bastante homogêneos em toda as fases e confiáveis para a identificação da espécie.

Os fatores abióticos existentes nas regiões de predominâncias das espécies do gênero Canavalia podem influenciar na sua morfologia.

\section{REFERÊNCIAS}

ABUD, H. F; GONÇALVES, N. R.; REIS, R. G. E.; GALLÃO, M. I.; INNECCO, R. Morfologia de sementes e plântulas de cártamos. Revista Ciência Agronômica. v. 4, n. 2, p.259-265, 2010. Disponível em: file://C:/Morfologia/727-3919-1PB\%20novo\%20220119.pdf

AGUIAR, R.B.A.; GOMES, J. R. C. Projeto cadastro de fontes de abastecimento por água subterrânea, estado do Piauí: diagnóstico do município de Ilha Grande. Fortaleza: CPRM - Serviço Geológico do Brasil, 2004. 7p. (Relatório Técnico).

AMARAL, M. C.; LEMOS, J. R. Floristic Survey of a Portion of the Vegetation Complex of the Coastal Zone in Piauí State, Brazil. American Journal of Life Sciences, v. 3, n. 3, p.213-218, 2015. Disponível em: <http://www.sciencepublishinggroup.com/j/ajls)>

doi: http://dx.doi.org/10.11648/j.ajls.20150303.22.

BARROSO, G.M.; MORIM, M.P.; PEIXOTO, A.L.; ICHASO, C.L.F. Frutos e sementes: morfologia aplicada à sistemática de dicotiledôneas. Viçosa: UFV, 2004. $443 p$.

BEYRA, A.; REYES, G.; HERNÁNDEZ, L. \& HERRERA, P. Revisión taxonómica del género Canavalia DC. (Leguminosae - Papilionoideae) en Cuba. Revista de la Academia Colombiana de Ciencias v. 28, p.157-175, 2004. Disponível em: https://www.researchgate.net/publication/268217429.

BORGES, R. C. F.; COLLAÇO JUNIOR, J. C.; SCARPARO, B.; NEVES, M. B.; CONEGLIAN, A. Caracterização da curva de embebição de sementes de pinhãomanso. Revista científica eletrônica de engenharia florestal, v. 8, n.13, p.1-8, 2009. http://dx.doi.org/10.1590/S0101-31222008000300014.

BRASIL. Regras para análise de sementes. Brasília, DF: Ministério da Agricultura, Pecuária e Abastecimento. 2009.

BRAZIL FLORA GROUP. Growing knowledge: an overview of Seed Plant diversity in Brazil. Rodriguésia, v. 66, n. 4, 2015.http://dx.doi.org/10.1590/21757860201566411.

CARVALHO, N. M.; NAKAGAWA, J. Sementes: ciência, tecnologia e produção. 5ed. Jaboticabal: FUNEP. 2012. 
CARVALHO, E. G. A.; TEODORO, M. S.; LEMOS, J. R. Inventario florístico de uma área ecotonal caatinga-cerrado no Norte do Piauí, Nordeste do Brasil. In: LEMOS, J. R. (Org). Pesquisas Botânicas e Ecológicas no Piauí. Curitiba: CRV. Coedição: Teresina, PI: EDUFPI, p. 35-54. 2018.

CERQUEIRA, E. C.; LEMOS, J. R. Levantamento florístico em trilhas naturais de um sitio com potencial turístico no norte do Piauí como subsídio à educação ambiental e conservação da fitodiversidade. In: LEMOS, J. R. (Org). Pesquisas Botânicas e Ecológicas no Piauí. Curitiba: CRV, 2018. Coedição: Teresina, PI: EDUFPI, p. 149159. 2018.

CORREA, G.C.; NAVES, R.V.; ROCHA, M.R.; CHAVES, L.J.; BORGES, J.D. Determinações físicas em frutos e sementes de baru (Dipteryx alata Vog.), cajuzinho (Anacardium othonianum Rizz.) e pequi (Caryocar brasiliense Camb.), visando melhoramento genético. Bioscience Journal, Uberlândia, v. 24, n. 4, p. 42-47, Oct./Dec. 2008

CRUZ E. D.; MARTINS F. O.; CARVALHO J. E. U. Biometria de frutos e sementes e germinação de jatobá-curuba (Hymenaea intermedia Ducke, Leguminosae Caesalpinioideae). Revistata brasileira de Botânica, v. 24, n. 2, p. 161-165, jun. 2001. Disponível em: <http://dx.doi.org/10.1590/S0100-84042001000200005>

DORIA, J. Generalidades sobre las semillas: su producción, conservación y almacenamiento. Cultivos Tropicales, v. 31, n. 1, p.74-85, 2010. Disponível em: <http://agris.fao.org/agris-search/search.do?recordID=CU2010401702>

DUARTE M. M.; MILANI J. E. F.; BLUM C. T.; NOGUEIRA A. C. Germinação e Morfologia de Sementes e Plântulas de Albizia edwallii (Hoehne) Barneby \& J. W. Grimes. Revista Caatinga. v. 28, n. 3, p. 166 - 173, jul/set., 2015. Disponível em: http://dx.doi.org/10.1590/1983-21252015v28n319rc.

DUARTE, M. M.; PAULA, S. R. P.; FERREIRA, R.L.; NOGUEIRA, A. C. Morphological characterization of fruit, seed and seedling and germination of Hymenaea courbaril L. (Fabaceae) ('Jatobá'). Journal of Seed Science, v.38 n.3, p.204-211, 2016. Disponível em: <http://dx.doi.org./101590/23171545v38n3159734>

DUTRA, F. V.; CARDOSO, A. D.; SILVA, R. M.; LIMA, R. S.; MORAES, O. M.; RAMPAZZO, M. C. Morfobiometria de frutos e sementes de Schizolobium amazonicum Huber ex Ducke. Revista Agropecuária Técnica. v. 38, n. 2, p. 58-64, 2017. Disponível em: <http://dx.doi.org/10.1590/1983-21252015v28n319rc.>

FELIPPI, M.; ARAÚJO, M. M.; LONGHI, S. J. Morfologia da flor, fruto, semente, plântula e muda de Cabralea canjerana (Vell.) Mart. CERNE, v. 21 n. 3, p. 387-394, 2015. Disponível em: <http://dx.doi.org./10.1590/01047760201521031466>

FERREIRA, R. A.; BARRETTO. S. S. B. Caracterização morfológica de frutos, sementes, plântulas e mudas de pau-brasil (Caesalpinia echinata LAMARCK) Revista Árvore. v. 39, n.3, p. 505-512. 2015. Disponível em: <http://dx.doi.org/10.1590/0100-67622015000300011> 
FELIPPI, M.; MAFFRA, C.R.B.; CANTARELLI, E.B.; ARAÚJO, M.M.A.; Longhi, S.J. Fenologia, morfologia e análise de sementes de Cordia trichotoma (Vell.) Arráb. ex Steud. Ciência Florestal, Santa Maria, v. 22, n. 3, p. 631-641, jul.-set., 2012. Disponível em: http://dx.doi.org/10.5902/198050986629.

GONÇALVES, I. P.; GAMA, M. C.; CORREIA, M. C. R. LIMA, H. A. Caracterização dos frutos, sementes e germinação de quatro espécies de leguminosas da restinga de maricá, Rio de Janeiro. Rodriguésia, v. 59, n. 3, p.497-512. 2008. Disponível em: <http://dx.doi.org/10.1590/2175-7860200859313>

LIMA, G. A.; TEODORO; M. S.; LEMOS, J. R. Estrutura de um trecho de vegetação subcaducifólia no extremo Norte do Piauí, Brasil. In: LEMOS, J. R. (Org). Pesquisas Botânicas e Ecológicas no Piauí. Curitiba: CRV, Coedição: Teresina, PI: EDUFPI. 2018.

LOPES, J.C.; MATHEUS, M.T. Caracterização morfológica de sementes, plântulas e da germinação de Dimorphandra wilsonii Rizz. - faveiro-de-wilson (FabaceaeCaesalpinioideae). Revista Brasileira de Sementes, vol. 30, no 1, p.96-101, 2008. Disponível em: http://dx.doi.org/10.1590/S0101-31222008000100013.

MARCOS FILHO, J. Fisiologia de sementes de plantas cultivadas. Piracicaba: FEALQ. 2005.

MENDONÇA, A. R.; FREITAS, T. A. S.; SOUZA, L. S. FONSECA, M. D. F.; SOUZA, J. S. Morfologia de frutos e sementes e germinação de Poincianella pyramidalis (Tul.) L. P. Queiroz, comb. Nov. Ciência Florestal, v. 26, n. 2, p. 375-387, abr.-jun., 2016. Disponível em: <http://dx.doi.org/105902/1980509822738>

OLIVEIRA, J. R.; COSTA, C. A. S.; BEZERRA, A. M. E.; ABUD, H. F.; LUCENA, E. M. P. Characterization of seeds, seedlings and initial growth of Jacaranda mimosifolia D. Don. (Bignoniaceae). Revista Árvore. v. 42, n. 4, 2018. Disponível em: <http://dx.doi.org/10.1590/1806-90882018000400003>

PEREIRA, V. S.; LEMOS, J. R. Levantamento florístico no povoado Pontal do Anel, Luís Correia, Piauí, Nordeste do Brasil. In: LEMOS, J. R. (Org). Pesquisas Botânicas e Ecológicas no Piauí. Curitiba: CRV. Coedição: Teresina, PI: EDUFPI, 123-147. 2018.

PINÃ-RODRIGUES, F. C. M.; AGUIAR, I. B. Maturação e dispersão de sementes In: AGUIAR, I. R.; PINÃ-RODRIGUES, F. C. M; FIGLIOLIO, M. B.(Ed.) Sementes Florestais Tropicais. Brasília: ABRATES, 215-74. 1993.

PONTES, M. S.; SANTIAGO, E. F.; NOBREGA, M. A. S.; FREITAS, V. M. B. Caracterização morfológica usando dimensões lineares sobre os atributos biométricos em sementes de Annona reticulata (L.) Vell. (Annonaceae). Ciência Florestal, v. 28, n. 2, p. 696-707, abr/jun., 2018. Disponível em: <http://dx.doi.org/10.5902/1980509832070>

PRADO, E. S.; RODRIGUES, R. S. Morfologia de frutos, sementes e plântulas de Canavalia dictyota Piper (Leguminosae, Papilionoideae). Boletim do Museu Integrado de Roraima v. 7, n. 1, p. 28 - 34, 2013.Disponível em: 
https://www.academia.edu/23283617/Morfologia_de_frutos_sementes_e_pl\%C3\%A2 ntulas_de_Canavalia_dictyota_Piper_Leguminosae_Papilionoideae.

QUEIROZ, M. S. M.; BIANCO, R. Morfologia e desenvolvimento germinativo de Oenocarpus bacaba Mart. (Arecaceae) da Amazônia Ocidental. Revista Árvore, v.33, n.6, p.1037-1042, 2009. Disponívle em: http://www.scielo.br/pdf/rarv/v33n6/a06v33n6.pdf

QUEIROZ, L. P.; SNAK, C. Canavalia in Lista de Espécies da Flora do Brasil. Jardim Botânico do Rio de Janeiro. Disponível em: $<$ http://floradobrasil.jbrj.gov.br/jabot/floradobrasil/FB82744>. Acesso em: 22 Set. 2018.

REIS, A. R.; FREITAS, A. D. D. F., LEÃO, N. V. M.; SANTOS FILHO, B. G. Morphological aspects of fruits, seeds, and seedlings, and anatomy of seedlings of Apuleia molaris spruce ex benth. Journal of Seed Science, v.38, n.2, p.118-128, 2016. Disponível em: <http://dx.doi.org./10.1590/2317-1545v38n2158472>

SILVA, K. B.; ALVES, E.U.; ALCÂNTARA BRUNO, R.L.A.; MATOS, V.P.; GONÇALVES, E.P.et al. Morfologia de frutos, sementes, plântula e plantas de Erytrhina velutina Willd. Leguminoseae - Papilionideae. Revista Brasileira de Sementes, v.30, n.3, p.104-114, 2008.

SILVA, A. K. C.; LEMOS, J. R. Florística de uma área de transição no Norte do Piauí, Nordeste do Brasil. In: LEMOS, J. R. (Org). Pesquisas Botânicas e Ecológicas no Piauí. Curitiba: CRV, Coedição: Teresina, PI: EDUFPI, p. 13-33. 2018.

SNAK, C. Canavalia in Flora do Brasil 2020 em construção. Jardim Botânico do Rio de Janeiro.Disponível em: <http://reflora.jbrj.gov.br/reflora/floradobrasil/FB82743>. Acesso em: 02 Mai. 2019.

THOMAZI, R.D.; ROCHA, R.T.; OLIVEIRA, M.V.; BRUNO, A.S.; SILVA, A.G. Um panorama da vegetação das restingas do Espírito Santo no contexto do litoral brasileiro. Natureza, v. 11, n. 1, p. 1-6, 2013.

VIDAL, W. N.; VIDAL, M. R. R. Botânica: organografia. 4.ed. Viçosa, MG: Universidade Federal de Viçosa, 2000. 114p. 